\title{
P-Selectin As A Marker of Platelet Activation in Africans with Prostate Cancer: A Cross-Sectional Study.
}

\author{
Dr. Hannah Omunakwe ${ }^{1}$ (MBBCh, DOccMed,FMCPath); Dr. Onyeanunam N. \\ Ekeke $^{2}$ (MBBS, FWACS); Dr. Christopher C. Obiorah ${ }^{3}$ (MBBS, FMCPath) \\ ${ }^{1}$ Haematology Unit, Pathology Department, Braithwaite Memorial Specialist Hospital; \\ ${ }^{2}$ Urology Division, Surgery Department, University Of Port Harcourt Teaching Hospital; \\ ${ }^{3}$ Histopathology Department, University Of Port Harcourt Teaching Hospital.
}

\begin{abstract}
Background: Platelets are components of blood involved in processes such as inflammation, metastasis and atherosclerosis by the use of adhesion molecules.sP-Selectin is a cellular adhesion molecule that promotes platelet-tumor cell interactions, venous thromboembolism and tumor metastasis. High plasma levels independently predict venous thrombosis in cancer patients and are known to play a major role in tumor metastasis. No study has determined the levels and associations of $s P$-selectin in prostate cancer patients in Africa.

Objectives: To evaluate $S P$-selectin levels in prostate cancer patients and assess the associations with increased values.

Methods: We prospectively enrolled 88 histologically diagnosed prostate cancer patients, reviewed their case notes for duration of presentingsymptoms, PSA at diagnosis, evidence of metastatic disease and history of comorbid states. Also, 40 healthy male controls were enrolled. Full blood count was done using EDTA samples and citrated samples for sP-selectin determination using ELISA for both groups of subjects.

Results: We found significantly reduced haemoglobin in cases than controls (10.79 $\pm 2.20 \mathrm{vs} 13.59 \pm 2.20 \mathrm{~g} / \mathrm{dl}$; $p=0.001)$, sP-selectin was significantly higher in cases (57.86 $\pm 69.92 \mathrm{vs} 25.83 \pm 9.72 \mathrm{ng} / \mathrm{l} ; \mathrm{p}=0.01)$. Twenty four patients $(27.3 \%)$ had sP-selectin levels $>53.1 \mathrm{ng} / \mathrm{ml}$ (mean $114.3 \pm 171.1 \mathrm{ng} / \mathrm{mL}$ ). sP-selectin was significantly higher in patients whose BMI was $>25 \mathrm{~g} / \mathrm{m}^{2}(p=0.03)$, those with 2 or more co-morbidities $(p=0.02)$ and more so in patients with diabetes mellitus $(p=0.009)$. sP-selectin was increased in metastatic cancer patients, although not significantly.

Conclusion: The findings from this study indicate that there is increased platelet activation in prostate cancer patients as measured by $s$-selectin, indicating a significant cardiovascular risk in these patients. Platelet activation was significantly associated with higher BMI and presence of co-morbidities. The ability of sPselectin to predict metastasis and risk of VTE in this environment needs to be elucidated in studies with larger cohorts.
\end{abstract}

Keywords: Platelet activation, P-selectin, Prostate cancer, Venous thromboembolism

\section{Introduction}

Platelet activation is associated with increased risk of venous thrombosis and patients with malignant conditions are at increased risk of thrombosis. P-selectin (CD62P) is an adhesion molecule stored within the agranules of platelets and the Weibel-Palade bodies of endothelial cells., When expressed on surfaces of cells, it is a marker of platelet activation.It is an endogenous lectin that can recognize sLe ${ }^{\mathrm{x}}$-containing mucins,which is used by the tumor cells to promote their progression to the metastatic phenotype. Malignant cells are able to express on their surface the ligand CD24, which has been identified to be a receptor for this adhesion molecule. When P-selectin interacts with this ligand on malignant cells, it enables the activation of platelet and endothelium, thus supporting metastasis. Platelet reactivity may mediate a final common pathway for venous thromboembolism in cancer patients.

The relationship betweencancersand thrombosis was first described by Trousseauover a decade ago and many studies have reported this association over the years. In the developed world, Cancer patients account for about $20 \%$ of the burden of VTE patients andof every seven patients with cancer who die in hospital, one dies effrom pulmonary embolism. Although post-mortem studies revealed 50\% incidence of thrombosis in cancer patients, generally, the risk factors for the development of VTE in cancer are varied and include: the age of the patient, sex, site of cancer, duration of illness, presence of co-morbidities, treatment modalities and level of supportive care. Prostate cancer is the leading cancer with significant morbidity in men of black African descent, the hospital incidence is 127/100,000 cases incidence in Nigeria and mortality as high as $64 \%$ has been reported within 2 years of diagnosis by one study. 
Prostate cancer is generally not associated with a high risk for VTE, however it has been reported that VTE in prostate cancer patients is a predictor of reduced survival especially in those with advanced disease.The treatment modalities for prostate cancer such as androgen deprivation therapy and chemotherapy are also associated with increased risk of thrombosis.There is no documented study of sP-selectin in prostate cancer patients in Africa that we are aware of, this study is aimed at determining the levels of sP-selectin in prostate cancer patients as compared with age-matched controls; as a way of evaluating platelet activation among prostate cancer patients.

\section{Patients and Methods}

The ethical committee of the University of Port Harcourt Teaching Hospital gave approval for this study. We prospectively enrolled 88 men with histologically diagnosed prostate cancer that were willing to participate in the study.These patients were either yet to commence treatment or had initiated only one form of the modalities of treatment for prostate cancer at the Urology division of the surgery department.The few early cases had either radical prostatectomy or brachytherapy; the advanced cases had androgen deprivation therapy (orchidectomy orgoserelin). Metastatic cases also had chemotherapy(docetaxel) and / or external beam radiotherapy. Castration resistant cases had low dose diethyl-stilbesterol, ketoconazole or abiraterone. Patients were recruited from the clinics or the wards. Patients who declined or had a past history of thrombotic disorder or anticoagulation therapy were excluded. Forty otherwise healthy male controls were also recruited. The weight and height of all the subjects was measured and their BMIs were determined using standard calculations. The clinical notes of the patients were also reviewed and information about the age, educational status, presenting symptoms, duration of symptoms before presentation, history of other co-morbidities, ECOG performance status, history of hospitalization, alcohol and tobacco use, histologic diagnosis, Gleason's score, PSA levels and treatment modality employed were documented on a proforma for each patient.

Full blood counts using EDTA samples were done within 30 minutes of sample collection using the KN1 3-part haemoanalyzer by Sysmex ${ }^{\circledR}$ and citrated samples were collected and centrifuged within 2 hours of collection at $2000 \mathrm{~g}$ for 20 minutes at room temperature to produce platelet-poor plasma; they were then transferred and stored in aliquots in a plasma tube at $-70^{\circ} \mathrm{C}$ till analyzed for sP-selectin determination using ELISA (R and D systems® UK).

\section{Results}

Between February2013 and October 2013, 88 eligible patients and 40 controls were enrolled. The general characteristics of the patients in the study are in Table 1, the age range of the patients was from 41 to 85 years, the peak prevalence of prostate cancer was in the 60-69 age category, 44(50\%). We found significantly reduced haemoglobin in cases than controls $(10.79 \pm 2.20 \mathrm{vs} 13.59 \pm 2.20 \mathrm{~g} / \mathrm{dl} ; p=0.001)$ and platelet count showed no significant difference $(243.14 \pm 150.85$ vs $226.80 \pm 53.83 ; p=0.503)$, however platelet count was significantly higher in hospitalized patients $(\mathrm{p}=0.03)$ and those with metastatic disease $(p<0.05)$, Table 2.

SP-selectin was significantly higher in cases than controls $(57.86 \pm 69.92$ vs $25.83 \pm 9.72 \mathrm{ng} / \mathrm{l} ; p$ $=0.01$ ), Figure 1. No statistically significant difference was observed between sP-selectin levels in study participants who had metastatic disease and those that did not, Table 3.No significant correlation was found between sP-selectin level and platelet count $(\mathrm{r}=-0.03)$ Figure 2 .

Twenty four patients $(27.3 \%$ ) had sP-selectin levels $>53.1 \mathrm{ng} / \mathrm{ml}$ (mean $114.3 \pm 171.1 \mathrm{ng} / \mathrm{mL}$ ). sPselectin was significantly higher in patients whose BMI was $>25 \mathrm{~kg} / \mathrm{m}^{2}(p=0.03)$, those with 2 or more comorbidities $(p=0.02)$ and more so in patients with diabetes mellitus $(p=0.009)$.

\section{Discussion}

P-selectin is an adhesion molecule that is stored in the $\square$-granules of platelets and Weibel-Palade bodies of the endothelial cells, which when activated; play a role in inflammatory cell adhesion process.There is a strong relationship between cancer and the activation of the haemostatic system. Increased sP-selectin levelhas been studiedas an indicator of platelet activation, a facilitator of metastasis and a marker of increased cardiovascular risk in many patient groups.It has been studied in some cancer groups as a predictive marker of cancer-associated thrombosis, indicator of prognosis and in mice models as indicator for metastasis. A cut-off sP-selectin level of $53.1 \mathrm{ng} / \mathrm{ml}$ was taken to be a significant risk to predict the occurrence of VTE in cancer in a large prospective study by Ay et al. In our study, sP-selectin level higher than $53.1 \mathrm{ng} / \mathrm{ml}$ in $27.3 \%$ of our patients indicating the risk for cardiovascular events in those patients.

Many of the patients in the study population presented late (Table 1).This is a common finding reported by other researchers from this region and it is associated with advanced disease states at presentation'. Ignorance, poverty and poor health seeking behaviour are responsible for the late presentation. The diagnosis of metastatic prostatic cancer was largely based on clinical and radiological evaluation as documented by the 
attending urologist in the patient's clinical notes. Investigations for metastasis were individualized and included isotope bone scan, Magnetic resonance imaging, and lumbo-sacral spine x-rays.

sP-selectin levels in this study were not related to the status of the tumors (metastasis, PSA or Gleason's score). The increase in SP-selectin levels was however related tohigh BMIs and increased medical comorbidities in this group of patients.Increased platelet activation in prostate cancer may be due to metastasis, androgen deprivation therapy, use of chemotherapeutic agents, stilbesterol and steroids. Some of our patients presented with paraplegia with attendant prolonged immobilization and increased risk of VTE. Most of the factors listed above are prevalent in our patients.

Medical co-morbidities have a dramatic effect on the development of VTE in cancer patients and also their survival.Increased co-morbidity is associated with increased occurrence of VTE in ovarian cancer however this relationship is not very strong for breast cancer. In Prostate cancer however, a cohort study of 44,035 Danish prostate cancer patients showed that increased co-morbidity was associated with increased rates of VTE in the cohort. The authors noted that $40 \%$ of prostate cancer patients already had co-morbidities before the diagnosis of prostate cancer.The current treatment of prostate cancer by androgen deprivation therapy is also a major risk factor for the development of cardiovascular event. The most common co-morbidities in our study are as documented in Table $\mathrm{x}$. Patients with diabetes mellitushad a significantly higher sP-selectin level $(\mathrm{p}=0.009)$ than those that did not have a diabetes. It may be necessary to observe these patients more closely and offer thromboprophylaxis for those at significant risk such as surgery, prolonged immobilization or obesity; as this may potentially improve prognosis.

In this study, patients who were overweight (BMI 25 - 29.99) had mean sP-selectin levels of $63.88 \pm$ $82.52 \mathrm{ng} / \mathrm{mL}$, while those who were obese (BMI > 30) had a mean sP-selectin of $138.33 \pm 117.25$. Clinical and epidemiological data support the relationship between obesity and thrombosis, and in the circumstance ofcancer the relationship may be stronger.

This study has some limitation as it is cross-sectional;it cannot directly imply a cause and effect interrelationship between platelet activation ormetastasis and formation of thrombosis in this group of patients. The small sample size may also be contributory.

\section{Conclusion}

Platelet activation is increased in prostate cancer patients in Africa just as shown in other parts of the world. Additionally, the study shows an association of increase sP-selectin with high BMI and medical comorbidity, especially diabetes mellitus. Larger observational studies may be helpful to identify patients with high sP-selectin that develop thrombosis and as this information may be useful in planning for thromboprophylaxis for patients with similar clinical presentation.

\section{References}

[1]. Wagner DD. The Weibel-Palade body: the storage granule for von Willebrand factor and P-selectin. ThrombHaemost. 1993;70:105-110.

[2]. Kim YJ, Borsig L, Varki NM \&Varki A (1998). P-selectin deficiency attenuates tumor growth and metastasis. Proceedings of the National Academy of Sciences, USA, 95: 9325-9330.

[3]. Friederichs J, Zeller Y, Hafezi-Moghadam A, Grone HJ, Ley K, Altevogt P. The CD24/ P-selectin binding pathway initiates lung arrest of human A125 adenocarcinoma cells. Cancer Res. 2000;60:6714-6722

[4]. Reyes-Reyes ME, George MD, Roberts JD, Akiyama SK. P-selectin activates integrinmediated colon carcinoma cell adhesion to fibronectin. Exp Cell Res. 2006;312:4056-4069.

[5]. Basu A, Gosain R, Tantry U, Miller K, Gurbel PA. Platelet Activation and Aggregation in Patients with Advanced Adenocarcinoma Undergoing Chemotherapy: Correlation with a Validated Venous Thromboembolism Risk Score. Blood 2015; $126(23)$

[6]. Trousseau A. Lectures on clinical medicine. Vol. 5. Hotel-Dieu, Paris: 1865. Phlegmasiaalbadolens; pp. 281-332. (Pubmed. Accessed May 9,2016)

[7]. Shen VS, Pollak EW. Fatal pulmonary embolism in cancer patients: is heparin prophylaxis justified? South Med J 1980; 73: 841-3

[8]. Neil Goldberg, Susan R. Kahn and Susan Solymoss.Markers of coagulation and angiogenesis in CAVTE. Journal of clinical oncology, 2003; 21(22):4194-4199.

[9]. Osegbe DN: Prostate cancer in Nigerians: facts and non-facts. J Urol 1997, 157(4):1340-1343.

[10]. Chaturvedi S, Sidana S, Elson P, Khorana AA, McCrae KR. Symptomatic and Incidental Venous Thromboembolic Disease Are Both Associated with Mortality in Patients with Prostate Cancer. PLoS ONE 2014; 9(8): e94048. doi:10.1371/journal.pone.0094048

[11]. Frenette PS, Wagner DD. Molecular medicine: adhesion molecules. N Engl J Med. 1996;334:1526 -1529

[12]. Ferroni P, Martini F, Riondino S, La Farina F, Magnapera A, Ciatti F, GuadagniF.Soluble P-selectin as a marker of in vivo platelet activation.ClinChimActa. 2009;399(1-2):88-91. doi: 10.1016/j.cca.2008.09.018.

[13]. Läubli H, Borsig L. Selectins promote tumor metastasis. Seminars in Cancer Biology, 2010; 20(3):169-177.

[14]. Ridker PM, Buring JE, Rifai N. Soluble P selectin and the risk of future cardiovascular events. Circulation 2001;103:491-5

[15]. Ferroni P, Roselli M, Martini F, D'Alessandro R, Mariotti S, Basili S. Prognostic value of soluble P-selectin levels in colorectal cancer.Int J Cancer. 2004 Sep 1;111(3):404-8.

[16]. Kim YJ, Borsig L, Varki NM \&Varki A (1998). P-selectin deficiency attenuates tumor growth and metastasis. Proceedings of the National Academy of Sciences, USA, 95: 9325-9330. 
[17]. Ay C, Simanek R, Vormittag R, Dunkler D, Alguel G, Koder S, Kornek G, Marosi C, Wagner O, Zielinski C, Pabinger I. High plasma levels of soluble P-selectin are predictive of venous thromboembolism in cancer patients - results from the Vienna Cancer and Thrombosis Study (CATS). Blood. 2008;112(7):2703-8.

[18]. Ekeke ON, Amusan OE, Eke N. Management of Prostate cancer in Port Harcourt Nigeria, changing patterns.JWACS. 2012; 2 (2)58-77.

[19]. Omunakwe HE, Ekeke ON, Eke N. Anaemia in Nigerian men with prostate cancer.IOSR Journal of Dental and Med. Sci. 2015; 14(4): 111-115.

[20]. Piccirillo JF, Tierney RM, Costas I, Grove L, Spitznagel EL., Jr Prognostic importance of comorbidity in a hospital-based cancer registry. JAMA. 2004;291:2441-2447

[21]. Eileen H. Shinn, Daniel J. Lenihan, Diana L. Urbauer, Karen M. Basen-Engquist, Alan Valentine, Laura Palmero,et al. Impact of cardiovascular comorbidity on ovarian cancer mortality. Cancer Epidemiol Biomarkers Prev. 2013 November ; 22(11): . doi:10.1158/1055-9965.EPI-13-0625.

[22]. Ording AG, Horváth- Puhó E, Garne JP, et al. Impact of comorbidity on risk of venous thromboembolism in patients with breast cancer: a Danish population- based cohort study. BMJ Open 2014;4:e005082. doi:10.1136/bmjopen-2014- 005082.

[23]. Ording AG, Horvath-Puho E, Lash TL, Ehrenstein V, Borre M, Vyberg M, Sørensen HT. Prostate cancer, comorbidity, and the risk of venous thromboembolism: A cohort study of 44,035 Danish prostate cancer patients, 1995-2011.Cancer.2015 Jul 6.doi: $10.1002 /$ cncr.29535.

[24]. Karzai $\mathrm{FH}^{1}$, Madan $\mathrm{RA}^{1}$, Dahut $\mathrm{WL}^{1}$. Future Oncol. Metabolic syndrome in prostate cancer: impact on risk and outcomes.2016 Apr [Epub ahead of print]

[25]. Samud F, Ruf W. Inflammation, obesity and thrombosis. Blood, 2013; 122(20):3415 - 3422. 